\title{
E-government principles: implementation, advantages and challenges
}

\section{Mohammed Alshehri}

School of Information and Communication Technology, Nathan Campus, Griffith University, 170 Kessels Road, Nathan, 4111, Queensland, Australia Fax: +617-373-55051

E-mail: mohammed.alshehri2@student.griffith.edu.au

\section{Steve J. Drew*}

Griffith Institute for Higher Education,

Gold Coast Campus,

Griffith University, 4222, Queensland, Australia

Fax:+617-555-28979

E-mail: s.drew@griffith.edu.au

${ }^{*}$ Corresponding author

\begin{abstract}
As internet growth provides new communication pathways and transaction models, many countries are positioning to take advantage of the possibilities for effective and efficient provision of government services to their populations. E-government is a form of information system and requires not only appropriate infrastructure to deliver it but also a level of e-readiness within government and the population. The objective of this paper is to review the available literature about e-government implementation stages, its challenges and benefits. This paper gathers and consolidates several relevant issues regarding e-government such as the definitions of e-government and e-readiness, classification of implementation stages, advantages of e-government implementation and particularly focuses on the challenges of e-government implementation. Analysing a brief study of Saudi Arabia's developing e-government programme indicates that most of the issues raised in the literature are relevant. It is expected that this review will form a conceptual basis for a new wave of research into effective e-government acceptance and adoption.
\end{abstract}

Keywords: e-government advantages; e-readiness; e-government challenges; e-government stages.

Reference to this paper should be made as follows: Alshehri, M. and Drew, S.J. (xxxx) 'E-government principles: implementation, advantages and challenges', Int. J. Electronic Business, Vol. x, No. x, pp.xxx-xxx.

Biographical notes: Mohammed Alshehri is a $\mathrm{PhD}$ candidate in the School of Information and Communication Technology at Griffith University in Queensland, Australia. He received his MSc in Computer and Communication Engineering from Queensland University of Technology in Brisbane, Australia, in 2007. 
Steve J. Drew is a Senior Lecturer in the Griffith Institute for Higher Education and Adjunct Research Fellow in the School of Information and Communication Technology at Griffith University's Gold Coast campus. His research work includes: engaging students with learning about information systems; developing teaching excellence with structured peer observation of teaching and e-systems, in which he heads an active research student team.

\section{Introduction}

E-government has become a popular focus of government efforts in many countries around the world. More and more governments have implemented and introduced e-government systems as a means of reducing costs, improving services, saving time and increasing effectiveness and efficiency in the public sector. E-government and internet has made an essential change in the whole society structure, values, culture and the ways of conducting business by utilising the potential of Information and Communication Technology (ICT) as a tool in daily work. The purpose of e-government is not only the conversion of traditional information into bits and bytes and making it reachable via the internet websites or giving government officials computers or automating old practices to an electronic platform, but it also calls for rethinking ways the government functions are carried out today to improve processes and integration.

Governments have used different strategies to build e-government. Some have created comprehensive long-term plans. Others have opted to identify just a few key areas as the focus of early projects. In all cases, however, the countries identified as most successful have begun with smaller projects in phases on which to build a structure. E-government researchers divide the process of e-government implementation into phases or stages. This paper presents information from different studies of e-government implementation; it will illustrate the advantages of implementing e-government systems and the most important challenges that affect the implementation and operation of those systems. Relevance of this information is reinforced as a brief analysis of citizen perspectives on challenges to current e-government development in Saudi Arabia is inspected.

\section{Definitions}

\subsection{E-government}

The term e-government has different definitions such as: "the delivery of government information and services online through the internet or other digital means" (West, 2001). Moreover, the United Nations Division for Public Economics and Public Administration (2001) define e-government as using the internet and the world wide web for delivering government information and services to citizens, business and other government agencies. Also, another definition was given by the World Bank (2001) as the utilising of ICTs for developing and improving the relationship between government, citizens, businesses and other government entities. Finally, Deloitte Research (2000) describe the 
e-government as the use of ICT, particularly the internet, as a tool for delivering better government services to the citizens, businesses and employees.

\subsection{E-readiness}

It is essential to introduce the e-readiness term (electronic readiness) in this paper, as it has been considered as one of the most important parts in the e-government implementation process. E-readiness is the ability to use ICT to develop one's economy and to foster one's welfare (Deloitte Research, 2000). Moreover, e-readiness as the Economist Intelligence Unit (2008) defines it as "a measure of the quality of a country's ICT infrastructure and the ability of its consumers, businesses and governments to use ICT to their benefit". In general, there are several benchmarking indices at the global level those calculated by the United Nations, the Economist Intelligence Unit (EIU), the World Bank and many others.

\section{Stages of e-government}

The implementation of e-government has a number of stages. This section reviews the stages of the implementation of e-government as obtained from the existing literature. It includes research done by Gartner Research (2000), United Nations (2001), Layne and Lee (2001) and World Bank (2002).

\subsection{UN/ASPA study: five stages of e-government model}

In the study "Benchmarking e-government: A Global Perspective, Assessing the Progress of the UN Member States", the United Nations Division for Public Economics and Public Administration (2001), identifies the five stages for quantifying progress of e-government. The study identifies e-government stages as representative of the government's level of development based primarily on the content and deliverable services available through official websites.

Stage 1: Emerging - An official government online presence is established through a few independent official sites. Information is limited, basic and static.

Stage 2: Enhanced - Government sites increase; information becomes more dynamic. Content and information is updated with greater regularity.

Stage 3: Interactive - Users can download forms, e-mail officials, interact through the web and make appointments and requests.

Stage 4: Transactional - Users can actually pay for services or conduct financial transactions online.

Stage 5: Seamless - Full integration of e-services across administrative boundaries allowing users to be task focused rather than department focused. Information is shared securely between departments to allow effective integration of e-functions and services. 


\subsection{Gartner study: four stages of e-government model}

To measure progress for e-government initiatives and to establish a road map to achieve the desired levels of constituency service, the Gartner Research (2003) study titled "Gartner's Four Phases of e-government Model" classifies e-government into four distinct phases. This can serve as a reference to position where a project fits in the overall evolution of an E-government strategy.

Stage 1: Presence - This stage is classified by a simple information-providing website of a passive nature, sometimes described as 'brochure ware', indicating the same level of functions as a paper brochure.

Stage 2: Interaction - The interaction stage offers simple interactions between governments and citizen $(\mathrm{G} 2 \mathrm{C})$, government to business $(\mathrm{G} 2 \mathrm{~B})$, or government agency to government agency (G2G). Interaction stage websites provide e-mail contact and interactive forms that generate informational responses.

Stage 3: Transaction - The transaction stage enables transactions such as paying for licence renewals online, paying taxes or fees, or submitting bids for procurement contracts.

Stage 4: Transformation - The highest stage, most closely aligned with the concept of governance, involves a reinvention of how government functions are conceived and organised.

\subsection{Layne and Lee study: four stage e-government model}

To help public administrators think about e-government and their organisations, Layne and Lee (2001) provided a four-stage e-government development and propose a 'stages of growth' model for fully functional e-government.

Stage 1: Cataloguing - In Stage 1 of cataloguing, initial efforts of state governments are focused on establishing an online presence for the government.

Stage 2: Transaction - In the transaction stage, e-government initiatives will focus on connecting the internal government system to online interfaces and allowing citizens to transact with government electronically.

Stage 3: Vertical integration - Vertical integration refers to local, state and federal governments connected for different functions or services of government.

Stage 4: Horizontal integration - Horizontal integration is defined as integration across different functions and services. In defining the stages of e-government development, the vertical integration across different levels within similar functionality is posited to precede the horizontal integration across different functions.

\subsection{World Bank study: three phases of e-government model}

To support decision and strategy makers in devising their own plans and initiatives, the US Center for Democracy and Technology (2002) divides the process of e-government implementation into three phases. These phases are not dependent on each other, nor 
need one phase be completed before another can begin, but conceptually they offer three ways to think about the goals of e-government.

Publish phase: Publish sites seek to disseminate information about government and information compiled by government to as wide an audience as possible. In doing so, publish sites serve as the leading edge of e-government.

Interact phase: Interactive e-government involves two-way communications, starting with basic functions like e-mail contact information for government officials or feedback forms that allow users to submit comments on legislative or policy proposals.

Transact phase: Allowing citizens to obtain government services or transact business with the government online. A transact website offers a direct link to government services, available at any time. Transact sites can enhance productivity in both the public and private sector by making processes that require government assistance or approval simpler, faster and cheaper.

\subsection{Comparison between e-government stages}

In the previous section, different stage models have been proposed from different sources. Despite their differences in terms of the number and names of proposed stages, there are many similarities between these stages. For example, presenting government information is commonly perceived as a first step to implementing e-government, despite the different names assigned to it (i.e., publish, cataloguing, presence, emerging and information publishing). Another common stage is the one in which all transactions are conducted online. This stage goes by different names such as transact, transactional and transaction. Moreover, two-way communication between government and other parties is also a common later stage, as observed within the (United Nations Division for Public Economics and Public Administration, 2001; Gartner Research, 2003; Center for Democracy and Technology, 2002) models. Also, Layne and Lee (2000) refer, albeit implicitly, to this stage when they state in their transaction stage that citizens can interact with the government electronically.

On the other hand, there are some differences between these models. For example, an enhanced stage is only mentioned by the United Nations Division for Public Economics and Public Administration (2001), which seeks to increase the number of websites and update process. So, it focuses on the growth of the e-government websites only through this stage of development. This reflects the importance of the internet as essential to the implementation of e-government. While Layne and Lee (2001) divide integration into vertical and horizontal stages. In the vertical stage, local, state and federal governments connected for different functions or services of government, so citizens are able to access the service at the higher level of governments (state and federal) from the same entry as the municipal portal because the local systems are directly connected to upper-level systems. At the horizontal stage, however "systems are integrated across different functions and services. For example, if any citizen made a transaction in one government department, this will lead to an automatic check against data held in other government departments (Layne and Lee, 2001).

In conclusion, it is clear that there is no specific number of stages of e-government since it is different from one researcher to another and presumably one country to another, due to a diversity of technological, social, organisational, economic and political 
reasons. What can be determined is that e-government involves multiple stages or phases of development and is not a one-step process.

\section{Advantages of e-government implementation}

Advantages and benefits of e-government implementation are the same for both developed and developing countries (Ndou, 2004). However, e-government applications have many benefits for citizens, business and government entities. E-government applications allow people, businesses and government sectors access to available government information $24 \mathrm{~h}$ a day, 7 days a week, which improves the quality of these services (Ndou, 2004). According to Seifert (2003), implementation of e-government will reduce cost and levels of organisational processes by streamlining and re-organising operating procedures. Moreover, the using of e-government systems will improve the performance of government agencies and that it will deliver public service effectively and efficiently for all customers (Rubin and Wang, 2004). In addition, Cohen and William (2002) declared that e-government has great benefits regarding economising and improving of government service operations, including efficiency, reduced transactional costs, increased transparency and increased services for citizens. Furthermore, Australia's National Office for the Information Economy (NOIE, 2003), now referred to as the Australian Government Information Management Office (AGIMO), identifies e-government benefits as follows:

- reduction of customers' and organisations' time, effort and costs

- improvement of service delivery and citizens' satisfaction

- increase in users' ICT skills, internet knowledge and computer usage

- creation of new business and work opportunities.

In addition, the Organisation for Economic Cooperation and Development (OECD, 2003) identified many advantages of e-government implementation such as:

- improves efficiency of government agencies in processing of data

- improves services through better understanding of users' requirements, thus aiming for seamless online services

- shares information and ideas between all government agencies and department to build one mega database

- assists a government's economic policy objectives by promoting productivity gains inherent in ICT and e-commerce

- improving transparency, accuracy and facilitating information transforming between government and customers

- helps in building trust between governments and citizens, an essential factor in good governance by using internet-based strategies to involve citizens in the policy process, illustrating government transparency and accountability. 
To conclude, it is clear that implementation of e-government not only saves resources, effort and money but also extensively increases service quality levels and reduces time spent in government departments (Seifert and Bonham, 2004).

\section{Challenges of e-government implementation}

There are different challenges and barriers that can delay progress of e-government implementation. The variety and complexity of e-government initiatives across the world implies the existence of a wide range of challenges and barriers to its implementation and management. This section will briefly introduce the most important and common challenges and barriers based on a review of extant literature. Challenges can be loosely grouped under the headings: technical barriers; organisational barriers; social barriers and financial barriers.

\subsection{Technical barriers}

The implementation of e-government consistently faces some technological difficulties such as lack of shared standards and compatible infrastructure among departments and agencies. Also, privacy and security of information are critical barriers in implementation of e-government from citizen concerns. A guarantee by the government will not suffice unless accompanied by technical solutions, transparency of procedures and possibly independent auditing (OECD, 2003).

\subsubsection{ICT infrastructure}

Lack or weakness of ICT infrastructure is one of the major challenges for e-government implementation. Internetworking is required to enable appropriate sharing of information and open up new channels for communication and delivery of new services (Ndou, 2004). For a transition to electronic government, there needs to be a technical and operational architecture, i.e., a guiding set of principles, models and standards.

Many developing countries suffer from the digital divide (referring to the gap in opportunity between those who have access to the internet and those who do not (OECD, 2003)), and owing to the lack of access to appropriate ICT infrastructure are not able to create an effective e-government deployment. The comparison of the digital divide between richer countries and developing ones is stark with high-income economies having 416 personal computers per 1000 people and low-income economies only 6 per 1000 (World Bank, 2003). However, an ICT infrastructure does not consist simply of telecommunications and computer equipment.

E-readiness and ICT literacy (ICT literacy is: using digital technology, communications tools, or networks to access, manage, integrate, evaluate and create information to function in a knowledge society) are also necessary in order for people to be able to use and benefit from e-government applications. Having the education, freedom and desire to access information is critical to e-government efficacy. Presumably, the higher the level of human development, the more likely the citizens will be inclined to accept and use e-government services (Ndou, 2004). Therefore, governments should work closely with the private sector to establish a modern infrastructure that will provide access opportunities to disconnected groups and 
individuals. This lack of infrastructure is cited as one of the primary barriers to egovernment implementation. Certain e-government applications require considerable investment in national IT infrastructure.

\subsubsection{Privacy}

Privacy is a critical issue in the implementation of e-government in both developed and developing countries. Layne and Lee (2001) identified privacy and confidentiality as critical barriers on the way to e-government implementation.

Privacy refers to the guarantee of an appropriate level of protection regarding information attributed to an individual (Basu, 2004). Seifert and Bonham (2004) emphasised that e-government should be approached with an eye towards the protection of individual privacy. Both technical and policy responses may be required when addressing the privacy issue in an e-government context. The difficulty of protecting individual privacy can be an important barrier to e-government implementation. In addition, there is a need to deal effectively with privacy issues in e-networks to increase citizen confidence in the use of e-government services. Citizen confidence in the privacy and careful handling of any personal information shared with governmental organisations is essential to successful e-government applications.

At the centre of most e-government projects is the collection and management of large quantities of citizen data such as names, addresses, phone numbers, employment histories, medical records and property records. In most western nations, citizens are deeply concerned with the privacy of their life and confidentiality of the personal data they are providing as part of obtaining government services. Thus, it has been pointed out that privacy and confidentiality must remain priorities when establishing and maintaining websites to ensure the secure collection of data. Since privacy protections are difficult to interject once an e-system has been built, the planning and design of e-government systems must include privacy considerations. A comprehensive privacy policy should specify citizens' rights to privacy and mandate that personal data be collected and processed only for legitimate purposes (Teeter and Hart, 2003). It is important to note that different countries have different legal and cultural understandings of what constitutes privacy (Seifert and Bonham, 2004). This highlights the importance of the next section regarding information security.

\subsubsection{Security}

In point of fact, security is one of the most significant challenges for implementing e-government initiatives. Many studies have found that security is one of the most important obstacles (Ebrahim and Irani, 2005; Layne and Lee, 2001). Security means protection of all information and systems against any disclosure to unauthorised access, or unauthorised modifications or devastation (Udo, 2001). Thus, it refers to protection of the information systems, assets and the control of access to the information itself (Basu, 2004). It is a vital component in the trust relationship between citizens and government. Security issues may present the largest obstacle to the development of e-government services.

Thus, security policies and standards that meet citizen expectations are an important step towards addressing these concerns (Sharma and Gupta, 2003). Smith (2002) emphasised that the use of security solutions, including digital signatures, encryption, 
user names, passwords, customer unique numbers, bank account numbers, and others being transmitted over the internet and stored electronically can help in fulfilling security goals in e-government applications. Furthermore, Seifert and Bonham (2004) point out that information security, referred to as cyber security or computer security, is an important e-government challenge.

In addition, security involves continuous vigilance and protection against the increasing danger of internet worms and viruses (Ebrahim and Irani, 2005). Also, people need to be educated on the importance of security measures, such as private passwords, to ensure their own protection. Teicher and Dow (2002) illustrate on the published record and a benchmark survey of Australian and US public managers to point out that security is considered to be a major barrier to the implementation of e-government by $36.8 \%$ of Australian respondents and by $37 \%$ of US respondents, with Australian respondents, ranking it the second most important obstacle to e-government implementation. Feng (2003) advised that, a body of security professionals should be set up to respond to threats and breaches. Also, the need for authority and an infrastructure encryption system has to be given top-priority.

\subsection{Organisational barriers}

The implementation of e-government is not a pure technical issue only, but rather an organisational issue (Feng, 2003). Organisational challenges include: lack of top management support, resistance to change to electronic ways, lack of inter-sector and inter-departmental collaboration, and lack of qualified personnel and training.

\subsubsection{Top management support}

The implementation of e-government requires the support from the leaders and top management of government for successful implementation. Top management support refers to the promise from leaders to accept, support and adopt the e-government systems and applications. Therefore, it plays a significant role in the adoption and implementation of e-government (Akbulut, 2003). In fact, leadership is one of the main driving factors in every new and innovative project or initiative, so it is necessary for the implementation of e-government (McClure, 2001). The support from high-level executives and operatives is vital to e-government development, the gaining of required resources and training, the cooperation and coordination between partners and stakeholders for the success of e-government implementation (Seifert and Bonham, 2004).

\subsubsection{Resistance to change to electronic ways}

E-government is a new phenomenon in many places, which in the work place means the transformation from manual methods of work to electronic ones. These new changes will create a new advanced environment completely different to what has been used for many years in government departments (Feng, 2003). Realin (2004) mentioned that many employees see e-government implementation as a threat to their positions and fear losing their jobs and power. However, to decrease resistance to e-government systems employees have to understand the importance and significance of e-government and be assured that their employment is not in danger. Through retraining and skill 
developments, the employees can be reassigned new roles. Moreover, it is important that e-government leaders identify the sources of resistance and create a plan for treating them (Working Group on E-Government in the Developing World, 2002).

\subsubsection{Collaboration}

Collaboration and cooperation between all partners or stakeholders is a critical factor in the e-government implementation process to gain a successful e-government system (Cohen and William, 2002). Ndou (2004) emphasised that cooperation between public and private sectors is necessary to provide resources, plans, skills and experiences that the government may not otherwise have. Government should encourage all sectors to participate in the e-government implementation and development.

\subsubsection{Lack of qualified personnel and training}

The lack of ICT skills is a major challenge to an e-government implementation, especially in developing countries (Ndou, 2004). The e-government system can be implemented successfully if qualified personnel are available to take the role of starting and developing the e-government system (Sharma and Gupta, 2003). In general, it is vital to focus on training and education programmes to enhance the progress of e-government projects. However, training is a fundamental prerequisite as the rate of change increases and new technologies, practices and competitive models appear. The full economic benefits of ICT depend on a process of training and learning skills, which is still at an important stage for all governments (OECD, 2003).

\subsection{Social barriers}

Social issues are mainly concerned with the usability of e-government systems by a large variety of people. This implies that the interface must be usable by all kinds of people within the government and the general populace. Social obstacles include many factors such as digital divide, culture, education and income. In this area, the first two factors will be illustrated but it should be noted that public education has been strongly linked to e-government success (Lee et al., 2005).

\subsubsection{Digital divide}

The digital divide refers to the gap in opportunity between those who have access to the internet and those who do not. Those who do not have access to the internet will be unable to benefit from e-government services (OECD, 2003). Thus, digital divide is "the gap between those with access to computers and the internet and those without" (Blau, 2002). Therefore, not all people have the suitable access to computers and internet, whether owing to a lack of income, necessary skills, or internet access. Smith (2002) recommended that making computers available in public locations, such as libraries, post offices and shopping centres, could help in addressing the digital divide. Feng (2003) points out that the lack of internet access among society was considered the most important barrier to e-government development. 


\subsubsection{Culture}

The main barriers to the adoption of e-government are not just technical, but also hinge on cultural implications of new technologies (Feng, 2003). Culture was defined as a set of important assumptions, beliefs and values that all members of a society share in common (Sathe, 1983). This implies that any change in opposition to societal norms is more likely to meet resistance. According to Davison and Martinsons (2003), "culture is difficult to study partially because it is not an easy concept to define". Cultural differences and individual behaviour patterns play a role in the acceptance and use of new technology (West, 2001). Chang (2002) identifies different factors of culture: social structure, education, language, religion, economic philosophy and political philosophy. Swartz (2003) found that cultural issues have negatively affected the acceptance and adoption of e-government system in some developed countries such as the UK and Japan. However, a cultural issue is not easily tangible, it must be given more planning so that technical change is implemented successfully (Weisinger and Trauth, 2003). What one can infer is that e-government acceptance will only start to be realised if it is introduced in a culturally sensitive manner. Adoption may require persistent but gentle pressure to insert innovation into a culture and make a population aware of its value.

\subsection{Financial barriers}

Moon (2002) declared that the lack of financial support is considered a significant obstacle to the implementation of e-government in many countries. It is necessary to ensure the availability of the existing and expected budgetary resources to achieve the goals. A most serious and significant barrier to the implementation of e-government is a lack of money; e-government implementation is expensive. Since every government budget is already overburdened with every possible expense budget makers can fit into it, the suggestion to expend the considerable sums that an excellent e-government will cost is a non-starter, in budgetary terms, and in budgetary politics (OECD, 2003).

Carvin et al. (2004) stated that because of the high cost of implementation and maintenance of the computer systems, many countries find a dilemma in funding e-government programmes, even when a government entity has a plan for effective and accessible e-government. Feng (2003) stated that a major obstacle to e-government, particularly in developing countries, is the lack of finance for capital investment in new technology. West (2001) noted that the abilities of government offices to place services online and to use technology for democratic outreach are hampered by budget considerations. Finally, the total cost, including the high cost of systems hardware and maintenance, softwares, training and education, are always seen as major barriers inhibiting agencies and governments from using the technologies.

\section{Discussion: a contemporary development perspective}

To demonstrate the relevance and applicability of the issues identified in the literature, a summary of perceived challenges to the development of e-government in Saudi Arabia is presented here. As part of a study to determine the barriers to adoption and diffusion 
of e-government in the Kingdom of Saudi Arabia (KSA), a survey pilot was carried out with a selection of its online (e-ready) citizens (Alshehri and Drew, 2010). As much of the literature regarding the development of e-government relates to that of the technologically developed nations prior to 2005 , it was of interest to see if the same challenges arise in a representative of the next wave of e-government development.

\subsection{Context}

KSA is one of the Oil Producing Economic Community (OPEC) nations and as such is considered a high-income 'developing' nation (WTO, 2004). AGOA, the African Growth and Opportunities Act (AGOA, 2011), defines developing countries as those that generally lack a high degree of industrialisation, infrastructure, capital investment, sophisticated technology, widespread literacy and advanced living standards amongst their populations. Saudi Arabia is undergoing rapid development as it seeks to invest its oil-derived wealth into developing a sophisticated knowledge-based economy for the future. The internet and telecommunications are increasingly commonplace in the major towns and cities and is quickly reaching to the more remote areas of the country. This provides the national infrastructure needed for e-government.

Development of e-government is part of the interest of KSA's ongoing 'Yesser' (meaning 'simplify') programme that was launched in 2005. This national e-government programme plays the role of the enabler and facilitator of the implementation of e-government in the country. Its vision is

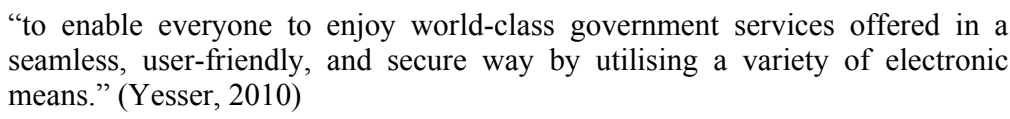

"to enable everyone to enjoy world-class government services offered in a seamless, user-friendly, and secure way by utilising a variety of electronic means." (Yesser, 2010)

It has not yet realised that vision for a number of reasons.

\subsection{Pilot study}

An invitation to complete a web-based survey was distributed to a number of 'e-ready' citizens. 123 respondents who regularly use web-based communications completed the survey providing the following demographic data: Age: $61 \%$ between 20 and 30 years old. Education: $75 \%$ have a Bachelor's degree or higher. Occupation: $65 \%$ government employees, $18 \%$ private sector employees. English proficiency: $82 \%$ average to good.

Questions, related to the literature review, were posed seeking what respondents felt were the most important challenges to the adoption of e-government from their perspectives. The following table identifies and ranks a number of the highly interrelated challenges perceived. The column headed 'Agreement' shows the percentage of the surveyed population that identified that challenge as significant.

Table 1 Challenges to e-government adoption

\begin{tabular}{llc}
\hline Rank & Challenges & Agreement (\%) \\
\hline 1 & IT infrastructural weakness & 62.8 \\
2 & Lack of public knowledge of e-government program & 56.5 \\
3 & Lack of security and privacy information & 46.6 \\
4 & Lack of qualified personnel and training courses & 44.7 \\
\hline
\end{tabular}


Table 1 Challenges to e-government adoption (continued)

\begin{tabular}{llc}
\hline Rank & Challenges & Agreement (\%) \\
\hline 5 & Culture differences (mismatch) & 33.8 \\
6 & Poor leadership and management support & 32.3 \\
7 & Lack of organisation policy and regulation for e-usage & 31.3 \\
8 & Lack of partnership and collaboration between agencies & 28.6 \\
9 & Lack of organisational strategic planning & 25.6 \\
10 & Resistance to change to e-systems & 19.3 \\
11 & Shortage of financial resources & 19 \\
\hline
\end{tabular}

It can be seen that some of these challenges relate directly to the status of the country as a wealthy developing nation. While the government is able to devote large sums of money to creating an e-government system, there are some important issues that cannot be instantly changed. Density of appropriate knowledge and experience to underpin the development and maintenance of systems is an issue that the KSA government is addressing by sponsoring student study abroad in many developed nations. International consultants also provide part of the solution while the IT discipline specific education is undertaken. IT Infrastructural weakness is a symptom of this stage of growth that inhibits both services and management.

E-government is aimed at more effective and efficient service provision to citizens and businesses. The above-mentioned data shows that there is poor public knowledge of e-government programmes, which will impact on the speed of uptake of any services that are developed. This suggests that a public education and awareness campaign will be helpful to ensure that all stakeholders are suitably prepared for this innovation.

Lack of IT discipline knowledge also underlies the poor leadership and management support for e-government and this is exacerbated by the poor public knowledge of the official e-government programme. Management will not be able to support or lead effectively without corporate or government policy and regulation to direct activities. Similarly without relevant knowledge and policy there can be no effective strategic planning for an organisation to develop e-government practice.

Culture in its many guises plays a significant part as a challenge to adoption of e-government. For generations, informal networks and person-to-person interactions, known as 'wasta', have typified the mode of transactions with government and large organisations. Individuals may not trust an organisation but they do trust people that they know to get things done for them. Islam is a major cultural influence in KSA and services need to be provided in a manner that is sensitive to the mores of this faith to be successful.

\subsection{Relevance of literature review to KSA's development}

The pilot survey, before, indicated that challenging issues revealed in the literature were very much relevant to the adoption and diffusion of e-government in KSA. Particularly those relating to poor technical infrastructure, concerns with privacy and security of information, management support, resistance to change, collaboration with other organisations, lack of qualified personnel, and aspects of culture are key aspects in need of attention. 
With Saudi Arabia's significant wealth and investment in e-government, the financial challenge indicated in literature is not an issue and this is reflected in the survey. Similarly with the country's rapid spread of telecommunications and the internet the digital divide is slowly being reduced. Currently, $50 \%$ of the Saudi population is less than 30 years old and are familiar with technology. This demography indicates that resistance to change is going to be a significant issue in most of the public sphere. Resistance to change in organisations is more likely to come from influential managers in another age demographic that are not quite so e-ready.

With regard to the staged development being a key to the successful implementation of e-government, it is apparent that each government department is taking a silo approach as they individually determine, design and implement the services that they can provide via the web. Without uniform government policy and regulation, there are no standards and therefore no platform for collaboration in the development of services. Statistics from the Yesser programme (Yesser, 2010) indicated that there were more than 180 electronic services offered by more than 50 different government organisations. Many of these have surpassed informative and interactive levels and are approaching the transactional level. Vertical and horizontal development sharing services and resources between levels of government and areas of government have not yet been recorded.

\section{Conclusion}

In summary, this paper highlights the different stages of e-government implementation, and the advantages and barriers to successful implementation of e-government system. It is clear that e-government involves multiple stages or phases of development as its use saturates different levels of government and the awareness and acceptance of the populace. It is apparent that e-government has many advantages to all sectors of government, citizens and business. Improving access, efficiency, and quality of services, to the public, business and other government departments are the fundamental aims underlying its development. However, the implementation of e-government is not an easy job, as it faces many challenges and barriers, which have to be treated very carefully.

Challenging issues can be broadly categorised into being social, financial, technological and organisation related with high levels of interrelatedness. In many of the western nations that started researching and implementing e-government in the early 2000s, solutions to the issues are currently still in different stages of advancement. Many more developing nations, particularly around the Middle East, are seeking to create effective online government services. This review of extant literature serves as summary of the findings relating to the first wave and as a brief reference for the next wave of e-government development.

Elsewhere (Alshehri and Drew, 2010), the authors have published the findings of a recent pilot study into challenges facing e-government adoption in the KSA. A synopsis was discussed here in relation to the findings from literature. Analysis shows that with some contextual differences, the new wave of e-government adoption in that developing nation shares many of the original issues raised in literature are currently challenges being faced. 


\section{References}

AGOA (2011) African Growth and Opportunities Act, "Trade Terminology", Accessed at: http://www.agoa.info/?view=trade\&story=terms\&startat $=\mathrm{d}$

Akbulut, A. (2003) An Investigation of the Factors That Influence Electronic Information Sharing between State and Local Agencies, Louisiana State University. AUTHOR PLEASE SUPPLY LOCATION.

Alshehri, M. and Drew, S.J. (2010) 'Challenges of e-government services adoption in Saudi Arabia from an e-ready citizen perspective', World Academy of Science, Engineering and Technology, Vol. 66. AUTHOR PLEASE SUPPLY PAGE RANGE.

Basu, S. (2004) 'E-government and developing countries: an overview', International Review of Law Computers, Vol. 18, No. 1, pp.109-132.

Blau, A. (2002) 'Access isn't enough', American Libraries, Vol. 33, No. 6, pp.50-52.

Carvin, A., Hill, J. and Smothers, S. (2004) E-government for all: Ensuring Equitable Access to Online Government Services, The EDC Center for Media \& Community and the NYS forum. AUTHOR PLEASE SUPPLY LOCATION.

Center for Democracy and Technology (2002) E-Government Handbook, Accessed on 22 October, 2009 from: http://www.cdt.org/egov/handbook

Chang, L. (2002) 'Cross-cultural differences in international management using Kluckhohn-Strodtbeck framework', Journal of American Academy of Business, Vol. 2, No. 1. AUTHOR PLEASE SUPPLY PAGE RANGE.

Cohen, S. and William, W. (2002) The Future of E-government: A Projection of Potential Trends and Issues, Columbia University. AUTHOR PLEASE SUPPLY LOCATION.

Davison, R. and Martinsons, M. (2003) 'Cultural issues and IT management: past and present', Guest Editorial, IEEE Transactions on Engineering Management, Vol. 50, No. 1, pp.3-7.

Deloitte Research (2000) At the Dawn of E-government, the Citizen as Customer, Accessed on 19 April 2010 from: http://www.egov.vic.gov.au/pdfs/e-government.pdf

Ebrahim, Z. and Irani, Z. (2005) 'E-government adoption: architecture and barriers', Business Process Management Journal, Vol. 11, No. 5, pp.589-611.

Economist Intelligence Unit (EIU) (2008) E-readiness Rankings 2008 Maintaining Momentum, Accessed on 22 October, 2009 from http://www.eiu.com

Feng, L. (2003) 'Implementing e-government strategy in Scotland: current situation and emerging issues', Journal of Electronic Commerce in Organizations, Vol. 1, No. 2, pp.44-65.

Gartner Research (2000) AUTHOR PLEASE SUPPLY FULL DETAILS.

Gartner Research (2003) Traditional ROI Measures Will Fail in Government, Accessed on 17/9/2009 from: http://www.gartner.com/resources/116100/116131/traditional_roi.pdf

Layne and Lee (2000) AUTHOR PLEASE SUPPLY FULL DETAILS.

Layne, K. and Lee, J. (2001) 'Developing fully functional E-government: A four stage model', Government Information Quarterly, Vol. 18, No. 3, pp.122-136.

Lee, S.M., Tan, X. and Trimi, S. (2005) 'Current practices of leading e-government countries', Communications of the ACM - The Digital Society, Vol. 48, No. 10, pp.99-104.

McClure, D. (2001) Electronic Government: Challenges Must be Addressed with Effective Leadership and Management, GAO-01-959T, Testimony before the Senate Committee on Governmental Affairs, on behalf of the US General Accounting Office, Accessed on 8/10/2009 at: http://www.gao.gov/new.items/d01959t.pdf

Moon, M.J. (2002) 'The evolution of e-government among municipalities: Rhetoric or reality?', Public Administration Review, Vol. 62, No. 4, pp.424-433.

National Office for the Information Economy (NOIE) (2003) E-government Benefits Study, Commonwealth of Australia, Canberra. 
Ndou, V. (2004) 'E-government for developing countries: opportunities and challenges', The Electronic Journal on Information Systems in Developing Countries, Vol. 18, No. 1, pp.1-24.

Organisation for Economic Cooperation and Development (OECD) (2003) The E-Government Imperative, OECD E-Government Flagship Report, Public Management Committee, Paris.

Realini, A.F. (2004) G2G E-government: The Big Challenge for Europe, University of Zurich. AUTHOR PLEASE SUPPLY LOCATION AND CHECK IF THE HIGHLIGHTED AUTHOR NAME IS 'Realin' or 'Realini'.

Rubin, B. and Wang, H. (2004) 'Embedding e-finance in e-government: a new e-government framework', Electronic Government, Vol. 1, No. 4, pp. 362-373.

Sathe, V. (1983) 'Implications of corporate culture: a manager's guide to action', Organizational Dynamics, Vol. 12, No. 2, pp.4-23.

Seifert, J. (2003) A Primer on E-government: Sectors, Stages, Opportunities, and Challenges of Online Governance, Report for Congress, Accessed on 14 October, 2005, from http://www. fas.org/sgp/crs/

Seifert, W. and Bonham, G. (2004) 'The transformative potential of e-government in transitional democracies', Public Management Electronic Journal, No. 2, pp.19-22. AUTHOR PLEASE SUPPLY VOLUME NUMBER.

Sharma, S. and Gupta, J. (2003) 'Building blocks of an e-government: a framework', Journal of Electronic Commerce in Organizations, Vol. 1, No. 4, pp.1-15.

Smith, B. (2002) E-government in Local Councils, Hunter's Hill Council. AUTHOR PLEASE SUPPLY LOCATION.

Swartz, N. (2003) 'British slow to use e-government services', Information Management Journal, Vol. 37, No. 7, pp.1-7.

Teeter, R. and Hart, P. (2003) The New E-Government Equation: Ease, Engagement, Privacy and Protection, The Council for Excellence in Government. AUTHOR PLEASE SUPPLY LOCATION.

Teicher, J. and Dow, N. (2002) 'E-government in Australia: promise and progress', Information Policy, Vol. 7, No. 4, pp.231-246.

Udo, G. (2001) 'Privacy and security concerns as major barriers for e-commerce: a survey study', Information Management \& Computer Security, Vol. 9, No. 4, pp.164-174.

United Nations (2001) AUTHOR PLEASE SUPPLY FULL DETAILS.

United Nations (2004) UN Global E-government Readiness Report, Toward Access for Opportunity, New York. AUTHOR PLEASE CITE THIS REFERENCE IN TEXT.

United Nations Division for Public Economics and Public Administration (2001) Benchmarking E-government: A Global Perspective - Assessing the Progress of the UN Member States, Accessed on 2/1/2010, from: http://pti.nw.dc.us/links/docs/ASPA_UN_egov_survey1.pdf

Weisinger, J.Y. and Trauth, E.M. (2003) 'The importance of situating culture in cross-cultural IT management', IEEE Transactions on Engineering Management, Vol. 50, No. 1, pp.26-30.

West, D.M. (2001) State and Federal E-government in United States, Available at: http://www. insidepolitics.org/egovt01us.html

Working Group on E-Government in the Developing World (2002) Roadmap for E-government in the Developing World. 10 Questions E-government Leaders Should Ask Themselves, Pacific Council on International Policy. Accessed at: http://unpan1.un.org/intradoc/groups/ public/documents/apcity/unpan005030.pdf

World Bank (2001) Issue Note: "E-Government and the World Bank", November 5, 2001. AUTHOR PLEASE SUPPLY LOCATION.

World Bank (2002) AUTHOR PLEASE SUPPLY FULL DETAILS.

World Bank (2003) World Development Indicators, Accessed from: http://www.worldbank. org/data/wdi2003/ 
WTO (2004) World Trade Organization, "Beyond Economic Growth Student Book", Accessed at: http://www.worldbank.org/depweb/english/beyond/global/glossary.html\#99

Yesser (2010) E-government Program, The Ministry of Communications and Information Technology, Available at http://www.yesser.gov.sa AUTHOR PLEASE SUPPLY INITIAL FOR HIGHLIGHTED AUTHOR. 